\title{
EDUCANDO NAS ÁGUAS DO PIRAJUÇARA - UMA PROPOSTA DE EDUCAÇÃO AMBIENTAL
}

\author{
*Denise de La Corte Bacci, **Ermelinda Moutinho Pataca, ***Pedro Roberto Jacobi, ****Paulo Augusto \\ Romera e Silva, *****Luiz Carlos Beduschi Filho
}

\section{RESUMO}

O artigo traz sua contribuição ao apresentar o curso de capacitação para professores da rede pública que enfoca os recursos hídricos e a Educação Ambiental. Interdisciplinar, visou trabalhar diversos conceitos usando a bacia hidrográfica do Pirajuçara como unidade territorial e ambiental, a partir dos aspectos físicos, históricos, sociais, econômicos e ambientais. Considerou também a participação da sociedade, a avaliação do significado da degradação ambiental nos recursos hídricos e a percepção da realidade na bacia, fornecendo subsídios para a formulação de projetos e ações de Educação Ambiental nas escolas. O curso foi elaborado pela articulação entre ensino e pesquisa, e com a divulgação de novas metodologias de ensino e do conhecimento sobre uma realidade local. As metodologias de ensino utilizadas partiram da contextualização espaço-temporal dos conhecimentos escolares, além da criação cartográfica e os estudos do meio. O curso proporcionou aos participantes uma compreensão no sentido real da palavra ambiental, em suas múltiplas características, que englobam o meio físico, o social, o histórico, o econômico e o político, promovendo uma visão socioambiental integrada da realidade local e ajudando-os na elaboração de projetos em sala de aula, usando os conhecimentos adquiridos.

Palavras-chave: Recursos hídricos. Bacia hidrográfica. Pirajuçara.

\section{ABSTRACT}

This contribution presents a training course for public school teachers which focuses on water resources and environmental education. Through an interdisciplinary approach, many conceptions such as physical characteristics, historical, social, economic and environmental aspects were developed using Pirajuçara river Basin as a territorial and environmental unity. Aspects such as society participation, an evaluation of environmental degradation in water resources and perception of the realty of the basin were considered, to give participants support to develop their own projects and actions in their schools. New methodologies, based on space and temporal knowledge and research of local realty, were presented and discussed with participants. Hydrographic basin models were constructed with cartographic representation of the terrain which associated with field work helped complete the panorama of Pirajuçara basin. As a result the course introduces a more integrated view of all socio-environmental issues in the local basin and helpes the teachers to elaborate their projects in the classroom using the acquired knowledge.

Key words: Water resources. Hydrographic basin. Pirajuçara.

* Instituto de Geociências (IGc-USP). ** Faculdade de Educação (FE-USP). *** FE-USP e Programa de Pós-Graduação em Ciência Ambiental (PROCAM-USP). **** Centro Tecnológico de Hidráulica (DAEE). ****** Escola de Artes, Giências e Humanidades (EACH-USP) e PROCAM-USP. 


\section{INTRODUÇÃO}

A presente contribuição visa discorrer sobre as atividades de extensão universitária que ocorreram durante o curso Educando nas Águas do Pirajuçara uma proposta de Educação Ambiental ${ }^{1}$, promovido pelos membros do TEIA-USP (Laboratório de Educação e Ambiente). O curso teve como objetivo trabalhar conceitos dos recursos hídricos, com ênfase na bacia hidrográfica do rio Pirajuçara, a partir dos aspectos físicos, históricos, sociais, econômicos e ambientais, a participação da sociedade, a avaliação do significado de degradação ambiental nos recursos hídricos e a percepção da realidade na bacia, fornecendo subsídios para a formulação de projetos e ações de Educação Ambiental nas escolas. O objetivo também foi o de estimular a troca de informações e experiências entre os participantes e o desenvolvimento de habilidades na utilização de meios de comunicação virtual para a formação de uma rede multiplicadora voltada para mudanças atitudinais que visem o uso sustentável da água.

O curso procurou, dessa forma, atender ao aperfeiçoamento de profissionais da rede pública da educação, nos termos da Lei Federal 9433/97, que aprovou a instalação da Política Nacional de Gestão integrada das águas no Brasil e da Lei Federal 9795/99, que trata da Política Nacional de Educação Ambiental. Nesse sentido, consideramos que o envolvimento em caráter continuado de professores como multiplicadores na difusão dos conceitos é da maior importância para que se coloque em prática, em nosso país, os princípios da sustentabilidade ambiental, envolvimento esse que foi atingido durante o curso.

Essa iniciativa teve a participação de diversas unidades da USP: do Instituto de Geociências (IGc), da Faculdade de Educação (FE), da Escola de Artes, Giências e Humanidades (EACH), do Programa de Pós-Graduação em Giência Ambiental (PROGAM) e do Centro Tecnológico de Hidráulica (DAEE),

I Projeto aprovado pelo Fomento às Iniciativas de Cultura e Extensão (antigo Fundo de Cultura e Extensão), da Pró-Reitoria de Cultura e Extensão Universitária da Universidade de São Paulo, intitulado Portal TEIA-USP de Educação Ambiental - inclusão digital para interação e aprendizagem como contribuição na melhoria da qualidade do ensino público. caracterizando uma ação interdisciplinar e interunidades, permitindo uma permanente interação entre diversos campos das ciências como motivação essencial no processo de ensino e aprendizagem.

O curso foi realizado em módulos presenciais, a cada I5 dias, nos quais foram desenvolvidos conceitos relacionados aos aspectos físicos, históricos e socioambientais dos recursos hídricos na bacia hidrográfica do Pirajuçara, e às metodologias de Educação Ambiental, incluindo conceitos de cidadania, sustentabilidade e participação. De forma completar às aulas presenciais, foram realizadas atividades por meios de comunicação virtual, no sistema da USP denominado Moodle, para estimular a inclusão digital nas escolas e o uso dos meios eletrônicos pelos professores na busca de informações e pesquisas. Durante a realização dos módulos presenciais e nas atividades a distância, os participantes, em grupos, foram estimulados a desenvolver projetos em assunto de seu interesse e da sua comunidade, já exercitando e aplicando os conceitos apresentados. Durante o curso contamos com a presença de alunos de pós-graduação e da graduação que auxiliaram na utilização da ferramenta Moodle. Os projetos em Educação Ambiental de interesse dos professores foram discutidos ao longo do curso, priorizando a sua interdisciplinaridade, o interesse e, muitas vezes, a dificuldade de elaboração de projetos pelas escolas, baseados em textos discutidos em aula e em referências fornecidas aos professores.

Os módulos foram integrados pela articulação entre os formadores, pelo ambiente virtual Moodle, pelas discussões interdisciplinares dos professores e, especialmente, pela proposição de uma atividade de campo integrada. O roteiro percorreu a bacia do $\mathrm{Pi}$ rajuçara e seus principais afluentes, com a observação in loco e discussão dos aspectos do meio físico, dos aspectos históricos, de uso e ocupação, dos problemas sociais e ambientais.

2 Contamos com a colaboração de dois bolsistas, Rodrigo Marinangelo de Vasconcellos e Juliana Pereira Silva, ambos alunos do curso de licenciatura em Geociências e Educação Ambiental e com financiamento do Fomento às Iniciativas de Cultura e Extensão da USP. 


\section{CONVERGÊNCIAS DE ABORDAGENS SOBRE ÁGUA NA EDUCAÇÃO - ATUAÇÃO DOS FORMADORES}

Um dos aspectos determinantes da configuração do curso proposto foi a atuação dos formadores em atividades de ensino e pesquisa, especialmente sobre a temática da água na educação, o que direcionou a escolha do tema, a proposição de metodologias de ensino, a divisão dos módulos de conteúdo e a articulação entre eles. Os integrantes do grupo TEIA-USP estão envolvidos em alguns projetos de ensino e pesquisa que contribuíram para a elaboração da proposta do curso Educando nas águas do Pirajuçara. Dessa forma, o curso foi elaborado pela articulação entre ensino e pesquisa e com a divulgação de novas metodologias de ensino e do conhecimento sobre uma realidade local.

O direcionamento inicial do curso partiu da definição da temática, comum na experiência didática dos professores, mas divergente em abordagens e perspectivas. Ao elaborarmos o curso de formação continuada, buscávamos uma temática ambiental compatível à realidade dos professores que contribuísse com sua formação de forma integradora, utilizando a interdisciplinaridade como princípio. Dessa forma, a utilização de uma bacia hidrográfica como unidade territorial e ambiental nos pareceu a melhor possibilidade para a discussão da problemática ambiental na região Oeste da cidade de São Paulo. Assim, delimitamos como área de estudo a bacia do Pirajuçara, que já tinha sido objeto de pesquisa em Educação Ambiental de alguns dos formadores e de seus orientandos.

$\mathrm{Na}$ literatura encontramos diversos projetos desenvolvidos em escolas com diferentes abordagens do tema água, mas todos articulando o currículo ao contexto da bacia hidrográfica: Leal \& Sudo (I997), Tundisi (2002), Silva (2003, in Pontuschka et al., 2007), Romera e Silva (2004), Compiani (2005), Hagy \& Villanova (2007); de La Corte \& Figueiredo (2007), Lucatto \& Talamoni (2007).

A principal referência sobre a bacia do rio Pirajuçara é o projeto Bacias Irmãs, que desenvolveu atividades acadêmicas focadas na pesquisa-ação e na capacitação de atores comunitários para promover maior envolvimento da sociedade civil na gestão das bacias hidrográficas. O projeto visou mobilizar as pessoas que vivem próximas a recursos hídricos, para participarem da gestão das águas e entenderem como a gestão de bacias hidrográficas funciona, com enfoque na Educação Ambiental (JACOBI, 2005). O projeto se insere numa preocupação em contribuir para o aperfeiçoamento e a democratização do gerenciamento das águas no país. O projeto surgiu em 2003, graças a uma parceria entre a Faculdade de Estudos Ambientais da Universidade de York, no Canadá, a USP (Agência de Inovação/PROGAM/ESALQ/ FE) e o Instituto Ecoar; e foi financiado pela Agência Canadense de Desenvolvimento Internacional.

Outra influência direta foi o projeto Elaboração de conhecimentos escolares e curriculares relacionados à ciência, à sociedade e ao ambiente na escola básica com ênfase na regionalização a partir dos resultados de projeto de Políticas Públicas, realizado na bacia hidrográfica do Ribeirão Anhumas, em Campinas ${ }^{3}$. Esse projeto utiliza-se da perspectiva local para a criação de currículos locais e sua execução influenciou na elaboração do curso, devido à participação de Ermelinda Pataca neste curso.

Como resultado dos projetos de pesquisa, os formadores criam uma produção bibliográfica sobre a temática da água na educação. Destacamos aqui a elaboração do artigo Educação para a Água (BACGI \& PATACA, 2008) que traz uma síntese bibliográfica e considerações metodológicas sobre a abordagem do tema água na educação e que fundamenta as considerações subsequentes nesta seção.

A utilização da bacia hidrográfica como unidade territorial e para a criação de currículos sobre a realidade local direciona a elaboração de algumas metodologias de ensino. O primeiro princípio que tratamos é da contextualização espaço-temporal dos conhecimentos escolares. Além disso, podemos utilizar da criação de modelos, como a construção de maquetes da bacia hidrográfica, a representação cartográfica e os estudos do meio. O conhecimento dos aspectos físicos da bacia hidrográfica, como geometria do canal fluvial, declividade, dimensionamento dos canais, área da bacia, associados a conceitos de vazão, balanço hídrico, anatomia e avaliação das cheias, foram abordados durante o

3 O projeto é uma parceria entre professores e pesquisadores do Instituto Agronômico de Campinas (IAC), Faculdade de Educação da Universidade de São Paulo (FE-USP), Instituto de Geociências (IGe) e Instituto de Biologia (IB) da Universidade de Campinas (Unicamp) e das Escolas Estaduais Adalberto Nascimento e Ana Rita Godinho Pousa. O projeto é coordenado pelo Prof. Dr. Maurício Compiani (IGe-Unicamp) e conta com financiamento da Fapesp e da Petrobras. 
curso para que a problemática ambiental, em particular o fenômeno das enchentes, pudesse ser compreendido de forma ampla. Ainda visando uma abordagem integrada dos fenômenos, procurou-se discutir as soluções dadas pelo poder público na solução das enchentes, como as obras hidráulicas de modificação na geometria dos canais fluviais e a construção de reservatórios de contenção, os denominados "piscinões", práticas muito comuns na cidade de São Paulo para solucionar esse tipo de problema. Para contextualizar os aspectos físicos com a realidade socioeconômica, diversos dados foram abordado a partir da literatura, dos quais podemos citar: Daee (I999), Ostrowsky (2000), Ipt (2004), Canil (2006), Seade (2007), Ipeadata (2007), Ibge (2007), Sempla (2007).

\section{ÁGUA NA EDUCAÇÃO}

O tema água pode estar presente no contexto educacional, tanto na educação formal como na não formal, com enfoque na ética e na formação do cidadão consciente do lugar que ocupa no mundo, num mundo real, dinâmico, que parte do local e se relaciona com o global, onde todas as coisas podem tomar parte de um processo maior, de um sistema integrado.

Ao abordarmos esse tema na educação não podemos tratar apenas dos usos que fazemos dela, mas da visão de que a água é um bem que pertence a um sistema maior, integrado, que é um ciclo dinâmico e natural sujeito às interferências humanas. Compreender a origem da água, o ciclo hidrológico, a dinâmica fluvial e o fenômeno das cheias, os aquíferos, bem como os riscos geológicos associados aos processos naturais (assoreamento, enchentes) é essencial para que possamos entender a dinâmica da hidrosfera e suas relações com as demais esferas terrestres.

Acreditamos que a água seja um tema de aproximação dos conhecimentos parcelares profundos e plurais e um tema que desenvolva a prática interdisciplinar. A construção de um programa que tenha a água como tema gerador, numa proposta de ação interdisciplinar, apoiada nos conceitos fundamentais, no valor explicativo e na função das Geociências, pode ser entendida pelos professores nas relações mais profundas entre esse conteúdo e a ação educativa, com envolvimento coletivo, dialógico e troca de saberes. Para Lorieri (2002), a escola deveria propiciar certa interligação entre os conteúdos para a compreensão de determinada realidade que não é fragmentada, mas prenhe de relações, e os projetos interdisciplinares auxiliariam na compreensão dessa realidade complexa e contraditória.

É possível tratar o tema água desde as primeiras séries do ensino Fundamental até o ensino Médio, com diferentes estratégias e recursos didáticos. Essa abordagem é necessária para atingir os objetivos pretendidos de formar cidadãos conscientes, capazes de julgar e avaliar as atividades humanas que envolvem o uso e a ocupação do ambiente, dentro e fora da comunidade em que estão inseridos.

A implantação de um programa baseado em fundamentos educacionais visa melhorar a qualidade de vida como meta de trabalho, formar adultos conscientes e professores capazes de formatar projetos sobre tais problemas e que sejam capazes de propor soluções para os problemas atuais. O desenvolvimento de trabalhos como esses, com participação na elaboração e no desenvolvimento, eleva a auto-estima e proporciona uma grande visibilidade à comunidade, aos professores e aos jovens.

Numa visão ainda mais ampla, a conscientização da comunidade, dos professores e dos jovens, em especial para os problemas de gestão e da qualidade das águas, deverá marcar as próximas décadas com problemas no abastecimento de água para a população, segundo estudos realizados pela ONU (Organização das Nações Unidas), em função, principalmente, da qualidade da água a ser consumida. Para tanto, é fundamental que o cidadão esteja consciente, seja informado dessa problemática e participe das discussões na sociedade, desenvolvendo sua capacidade de atuação de forma preventiva em questões como, por exemplo, a preservação dos mananciais e das áreas de proteção ambiental e os problemas que são gerados pela urbanização e ocupação de áreas de risco.

Nesse mesmo contexto, insere-se o desenvolvimento de conceitos como sustentabilidade, cidadania e participação, fazendo com que cada participante entenda e se integre aos problemas da sua comunidade e, em especial, no que diz respeito aos recursos hídricos, mais especificamente em âmbito local (JACOBI, 2003).

Uma comunidade consciente do bem estar comum certamente terá um futuro diferente do que hoje projetam os especialistas, pois os recursos hídricos são, sem dúvida, o elemento principal para 
o desenvolvimento e para uma melhor qualidade de vida, considerando as expectativas dos mais diversos segmentos.

\section{A BACIA HIDROGRÁFICA DO PIRAJUÇARA - LOCALIZAÇÃO E HISTÓRICO DA REGIÃO}

A bacia hidrográfica do rio Pirajuçara (figura I), afluente da margem esquerda do rio Pinheiros, está localizada a oeste da Região Metropolitana da Grande São Paulo (RMSP), ocupando uma área de 73, I km2. De acordo com a divisão político-administrativa, abrange os municípios de São Paulo, com 40,6 km2 (região da subprefeitura do Butantã, com 23,4 km2 e da subprefeitura de Campo Limpo, com I7,2 km2), Embu, com 12,3 km2 e Taboão da Serra, com 20,2 km2. Faz parte do Comitê da Bacia Hidrográfica do Alto Tietê (CANIL, 2006).

\section{FIGURA 1}

Localização geográfica da bacia do rio Pirajuçara

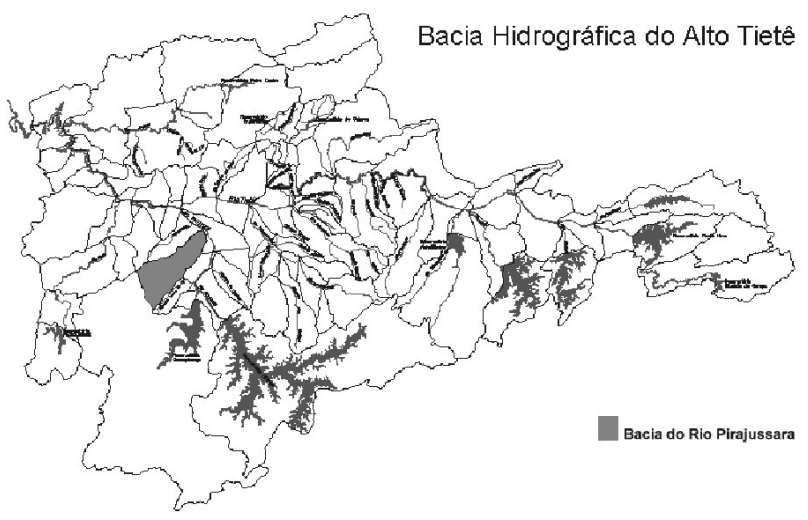

Segundo dados do censo (IBGE, 2007), a bacia do Pirajuçara possui aproximadamente 678.267 habitantes e o seu principal problema são as inundações que ocorrem periodicamente no curso principal e nos seus afluentes (ribeirão Poá e Joaquim Cachoeira).

O problema das enchentes que atingem a bacia há mais de 20 anos tem se agravado diante das modificações no uso e ocupação do solo. Em linhas gerais, a expansão urbana, a partir do desmatamento, parcelamento de terra e adensamento das edificações, atingiu terrenos que, devido às suas características naturais, não menos favoráveis à ocupação, apresentavam-se suscetíveis ao desenvolvimento de processos erosivos (CANIL, 2006).

Estudos realizados na Região Metropolitana de São Paulo revelam que, dentre os maiores problemas ambientais está a erosão acelerada (IPT, 2004). As alterações na morfologia dos terrenos, expondo solos frágeis, mudanças nas características hidrológicas das bacias com o incremento do escoamento superficial, redução do tempo de concentração das águas pluviais, intensificação dos picos de cheias e outras modificações, resultam em processos de erosão e transporte dos solos muito mais intensos que as áreas de uso rural. No caso da bacia do Alto Tietê, que corresponde à área da RMSP, esses impactos podem ser identificados em diversos rios e córregos que compõem o referido sistema hidrográfico, como o rio Pirajuçara (CANIL, 2006).

A paisagem do rio Pirajuçara, hoje drasticamente transformada pelas ações antrópicas, evidencia um cenário comum da realidade brasileira: a ocupação irregular das áreas de mananciais, visivelmente desordenada, em trechos dos municípios de Taboão da Serra, Embu e São Paulo, afetando a qualidade da água do rio, não só destruindo os remanescentes da flora e fauna, mas prejudicando também, a qualidade de vida da população.

Percebe-se, portanto, que o histórico da região é marcado pelas catástrofes e grandes perdas materiais com a ocorrência frequente de grandes enchentes e inundações, levando o governo, juntamente com as manifestações populares, optarem por soluções, muitas vezes imediatistas: canalização das margens dos córregos e rios e a construção de piscinões.

Além da canalização do Pirajuçara, os piscinões passaram a ser a solução para as inundações na região. Com a construção de cinco piscinões (Parque Pinheiros - Taboão da Serra/ São Paulo, Jardim Independência - Embu, Maria Sampaio - Embu/ São Paulo, Portuguesinha - Taboão da Serra e Eliseu de Almeida - Taboão da Serra/ São Paulo), surgem outros problemas, principalmente para os moradores do entorno. O mau cheiro, a presença de ratos e insetos, e a poluição causada pela falta de limpeza e de manutenção das margens são alguns dos incômodos provocados por esses terrenos destinados à concentração das águas nos períodos das chuvas.

A região da bacia do rio Pirajuçara é caracterizada 
por uma grande diversidade socioeconômica, apresentando heterogeneidade nas condições de vida da população residente e no uso e ocupação do solo. As populações da área são predominantemente de baixa renda (IBGE, 2007). A heterogeneidade socioeconômica da ocupação urbana foi um dos fatores determinantes da subdivisão da bacia do rio Pirajuçara em dois setores: o inferior, abrangendo a área da foz até a confluência com o ribeirão Poá, com características ocupacionais de média a alta renda, e o superior, desse ponto até a nascente, predominantemente de baixa renda. Neste setor há maior concentração de favelas, com maior ocorrência de lixo jogado no rio e esgotos em vala negra, causando assoreamento e poluição no canal, fato esse que contribui para a ocorrência de doenças de veiculação hídrica.

\section{OS PROFESSORES E SUAS MOTIVAÇÕES}

Outro fator determinante da dinâmica do curso foi o perfil dos professores envolvidos. Ao pensar em um curso estruturado para uma realidade local, definimos inicialmente que este seria direcionado para professores que atuassem em escolas na bacia do $\mathrm{Pi}$ rajuçara. Essa abordagem condiz com nossa proposta romper com as fragmentações disciplinares e buscar a integração entre os saberes relacionados a uma microbacia urbana. A identidade do grupo se deu, então, por meio da busca de conhecimentos sobre a realidade socioambiental do Pirajuçara, o que enriqueceu as discussões e a contribuição dos professores com registros sobre a realidade do local, como fotografias antigas, recortes de jornal ou mesmo o depoimento sobre o processo de ocupação do território, as enchentes e toda a problemática ambiental vivenciada por eles, moradores na bacia do Pirajuçara ou funcionários de escolas da região.

O curso contou com a presença de 27 professores da rede pública estadual e municipal dos municípios localizadas na bacia hidrográfica do Pirajuçara, ou seja, região Oeste de São Paulo (bairros do Butantã e Pinheiros), Taboão da Serra e Embu. Os professores que frequentaram o curso responderam sobre sua área de atuação e o interesse que os moveu a fazer o curso. O gráfico I mostra a distribuição por área de atuação dos professores inscritos.

\section{GRÁFICO 1:}

Distribuição por área de atuação dos professores que frequentaram o curso.

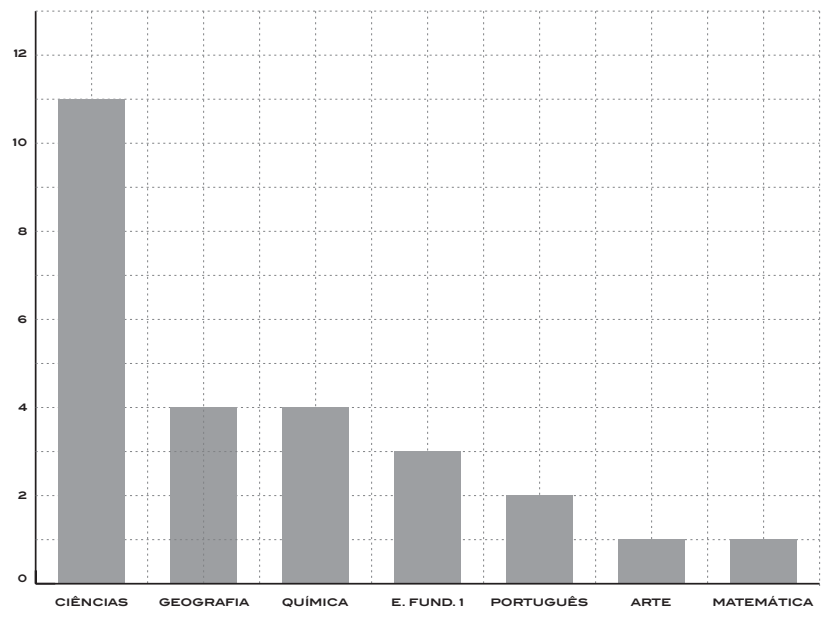

O perfil da turma foi extremamente relevante para a condução do curso, através dos interesses e discussões que os professores apresentaram. Podemos observar a predominância de professores de Ciências que procuraram o curso, o que revela uma demanda de conhecimentos ambientais por essa disciplina. Porém, a turma era bastante interdisciplinar e tínhamos também professores de Geografia, Português, Artes, Matemática e do ensino fundamental I. As discussões promovidas no curso foram extremamente ricas devido à troca de experiência e de diferentes linguagens dos professores com formações diversificadas.

Quanto à motivação, as respostas mais frequentes foram:

- aprofundar os conhecimentos sobre a questão das águas e práticas de Educação Ambiental (I4 respostas);

- busca de conhecimentos sobre os impactos socioambientais, sobre a história da região e sobre as soluções para problemas locais (6 respostas);

- busca por conhecimentos específicos sobre a origem da água no planeta, alimentação de rios, lagos, funcionamento da bacia hidrográfica, ciclo hidrológico e o problema das enchentes (5 respostas);

- busca por uma visão multidisciplinar e não compartimentada do conhecimento (I resposta).

Em razão do atendimento à demanda dos professores e da necessidade que eles apresentaram em 
desenvolver uma visão integrada da realidade, o curso forneceu subsídios para que todos pudessem rever seus currículos, reformulando-os numa perspectiva local, e criou oportunidade da prática da interdisciplinaridade, da integração e da discussão do papel da escola diante das realidades ambientais. Dessa forma, o curso visou, também, como um importante objetivo, desenvolver uma maior autonomia de atuação na realização de projetos, como forma de garantir a melhoria de qualidade no ensino e ampliação do interesse local.

\section{CONTEÚDO E METODOLOGIA DE DESENVOLVIMENTO DO CURSO}

O conteúdo programático do projeto foi distribuído em quatro módulos de acordo com a atuação dos professores e da relevância das abordagens para um estudo integrado da bacia hidrográfica. Foram ministradas seis aulas presenciais de 4 horas, um módulo de trabalho de campo de 8 horas e uma oficina para elaboração de maquete, também de 8 horas. As atividades a distância complementaram a carga didática em mais 40 horas. O programa ofereceu um amplo panorama dos aspectos físicos, históricos, sociais, econômicos e ambientais no uso da água, em particular na bacia hidrográfica do Pirajuçara e da sua gestão, baseados nos princípios da Lei 7663/9I, que regulamenta a Política Estadual de Gestão de Recursos Hídricos e da Lei Federal 9795/99, que trata da Política Nacional de Educação Ambiental.

\section{MÓDULO 1 - EDUCAÇÃO AMBIENTAL, SUSTENTABILIDADE E PARTICIPAÇÃO}

O módulo foi conduzido pelo Prof. Dr. Pedro Jacobi e pelos doutorandos Paulo Marco C. Gonçalves e Maria Isabel Franco. O programa priorizou leituras de aprofundamento teórico das práticas de Educação Ambiental e de aquisição de um repertório sobre a cultura da sustentabilidade em suas múltiplas dimensões, considerando as práticas sociais, o tema da cidadania e a dimensão cultural num contexto permeado pela ampliação dos problemas ambientais. Foram abordadas as relações entre educação e meio ambiente, com ênfase nos temas da sustentabilidade e da participação social como eixos que estimulam o desenvolvimento de um pensamento crítico.

Foram discutidas as questões ambientais e o papel do educador na busca por enfrentá-las. Os desafios de ampliar os conteúdos educativos e práticas de cidadania, educando para as dificuldades provocadas pelos diferentes processos de degradação das condições ambientais, foram enfatizados mostrando a responsabilidade do poder público, mas também a responsabilidade individual e dos grupos, e da população de forma geral no enfrentamento dos problemas sociais e ambientais.

Ressaltou-se que a educação tem o desafio de trazer uma visão de mundo de que as questões ambientais fazem parte da vida de cada cidadão e não são preocupações exclusivas do governo. A partir dessa discussão foram dados muitos exemplos em relação ao uso da água e à disponibilidade hídrica, principalmente nas regiões metropolitanas, que sofrem com a poluição, a falta de saneamento e mesmo do próprio recurso.

Como atividade deste módulo foram propostas duas perguntas que os alunos deveriam responder através do ambiente Moodle.

\section{MÓDULO 2 - CICLO DA ÁGUA NO PLANETA - ASPECTOS TEÓRICOS E METODOLÓGICOS}

Este módulo foi conduzido pela Profa. Dra. Denise de La Corte Bacci e pelo Dr. Paulo Augusto Romera e Silva. A abordagem sobre a origem da água no planeta foi desenvolvida com uma atividade prática denominada Fita do Tempo Geológico, na qual se procurou dar uma noção da idade do planeta Terra e contextualizar a origem da água com a sua origem, para que então pudéssemos entrar na discussão atual de disponibilidade e demanda dessa substância na sociedade. Foram abordados os aspectos geológicos de formação do planeta e a escala de tempo geológico (TEIXEIRA et al., 2009), conceitos que foram muito importantes para a compreensão do ciclo hidrológico na Terra.

A segunda aula abordou as questões atuais relacionadas aos usos múltiplos dos recursos hídricos, a disponibilidade e demanda de água, a conceituação de bacia hidrográfica, com exemplos brasileiros e enfoque na bacia do Pirajuçara. Abordou ainda os processos naturais das enchentes e os cálculos hidráulicos necessários para a contenção das mesmas em áreas urbanas, 
especialmente o caso da bacia do Pirajuçara, que se encontra hoje quase que totalmente impermeabilizada e sofre com essa problemática. Acreditamos que o conhecimento dos aspectos físicos da bacia esclareceram muitas dúvidas dos professores, tanto em relação a conceitos como em relação ao próprio funcionamento dos ciclos naturais. Essa abordagem foi fundamental para a compreensão dos problemas ambientais para a região e da visão integrada da bacia hidrográfica para propor soluções aos problemas atuais e às políticas públicas empregadas.

\section{OFICINA TEMÁTICA DE BACIA HIDROGRÁFICA}

Esta oficina foi conduzida por Renata Tonet, do Centro Paula Souza e foi baseada na construção de uma maquete de bacia hidrográfica, utilizando mapa topográfico e diversos materiais de uso comum nas escolas (canetinhas, tesoura, cola e papel Paraná), mostrando como essa atividade pode ser facilmente desenvolvida em sala de aula com alunos de diversas faixas etárias e mostrando a importância do relevo e da constituição geológica local para a formação e desenvolvimento das bacias hidrográficas. A oficina foi muito importante nesta fase do curso para trabalhar o conceito de bacia hidrográfica e preparar os professores para a aula de campo, com a visão integrada de bacia, dos divisores e de como a interferência humana pode modificar os sistemas naturais.

\section{MÓDULO 3 - ÁGUA: ASPECTOS HISTÓRICOS E GEOGRÁFICOS}

Este módulo foi conduzido pela Profa. Dra. Ermelinda Moutinho Pataca. A história ambiental de um determinado lugar pode ser mais bem compreendida quando inserida no tempo geológico, a partir do qual se conhecem a história e a origem do planeta Terra, compreende-se a dinâmica do sistema em que estamos inseridos e do qual fazemos parte, os fenômenos que se sucederam ao longo de bilhões de anos e as transformações ocorridas nesse período. Além disso, serve para promover a percepção dos processos naturais além do ciclo de vida humano e entender o potencial das ações antrópicas sobre o meio natural, ocupando um importante papel nas relações existentes entre o ambiente e a sociedade (BACGI \& PATAGA, 2008).

Dessa forma, este módulo histórico se complementa profundamente ao módulo geológico, especialmente na interpretação do ambiente de forma contextualizada no tempo e no espaço. O objetivo do módulo era discutir algumas possibilidades para abordar a história do ambiente que estava sendo estudado. Assim, começamos uma discussão com a elaboração de um questionário sobre as concepções de história e de como os professores abordavam a ciência e o ambiente, sob uma perspectiva histórica em suas aulas.

Foi solicitado aos professores que apresentassem suas questões, o que gerou uma rica discussão sobre as diversas perspectivas sobre história, ciência e ambiente dos professores e diferentes abordagens didáticas. A multiplicidade de perspectivas deveu-se à atuação dos professores em disciplinas distintas, o que levou a uma troca de experiências e saberes.

Num segundo momento do módulo, apresentamos em uma aula expositiva a temática "A água no Brasil colonial", já abordada em outros cursos de formação de professores e que mostra a importância dos cursos hídricos para formação, ocupação territorial e exploração dos recursos naturais durante o período colonial brasileiro. A abordagem utilizada foi da relação histórica entre ciência, tecnologia, sociedade e ambiente. Foi feita uma contextualização histórica sobre os usos da água durante o período colonial brasileiro, destacando-se os condicionantes naturais para a navegação que configuraram a formação do Império português entre os séculos XV e XVIII. Além disso, destacamos a configuração das bacias hidrográficas brasileiras associadas às condicionantes de navegação fluvial como fatores determinantes para a expansão territorial e da divisão política da América Portuguesa.

A água também foi um elemento estruturador da urbanização, na qual havia um planejamento para a construção de cidades em pontos estratégicos na costa brasileira e na foz de alguns rios durante o período colonial. Além disso, alguns traçados urbanos também seguiam a configuração dos rios, pela importância da água em todas as atividades do cotidiano das populações. Na perspectiva tecnológica, a água representou grande importância no desenvolvimento agrícola e industrial no Brasil, pois era uma das principais fontes de força motriz para os engenhos agroindustriais, de 
mineração e a separação dos minérios. Essa construção histórica é realizada com a análise de textos em associação com imagens, como cartas marítimas e fluviais; perfis de cidades; planos urbanísticos.

A abordagem histórica dos usos da água no Brasil despertou muito interesse nos professores, em especial no que diz respeito a políticas de governo que foram adotadas desde o tempo do descobrimento pelos portugueses e que se refletem ainda hoje no nosso país. Foi possível demonstrar que a interpretação histórica do ambiente é essencial para compreendermos os processos de transformação, as simbologias de utilização dos recursos naturais associadas à cultura de cada período histórico.

\section{MÓDULO 4 - ÁGUA: ASPECTOS SOCIAIS, ECONÔMICOS E INSTITUCIONAIS}

Esse módulo foi conduzido pelo Prof. Dr. Luiz Carlos Beduschi. Relações entre as dimensões sociais, econômicas e institucionais na gestão da água. Olhar sobre a política das águas, destacando a Política $\mathrm{Na-}$ cional dos Recursos Hídricos, a situação no estado de São Paulo e especificamente na Região Metropolitana de São Paulo. Destaque para os aspectos econômicos cobrança da água e outros mecanismos - e para a análise sobre o impacto dos problemas sociais na qualidade de vida e na gestão dos recursos hídricos. Legislação Nacional e Estadual de Recursos Hídricos. Diversos documentos.

Esse módulo teve como objetivo principal discutir as dimensões sociais, econômicas e institucionais na gestão da água e olhar para a perspectiva da Educação Ambiental como instrumento de auxílio para a gestão. A partir de uma abordagem dialógica, os alunos foram instigados a discutir questões relacionadas à problemática da água e a propor soluções para os problemas, com um enfoque global e local. Muitos professores levantaram questões de ordem local, dos problemas que enfrentam para a abordagem do tema em sala de aula e, juntos com o professor, encontraram algumas respostas.

\section{ATIVIDADE INTEGRADA: CONHECENDO A BACIA HIDROGRÁFICA EM QUE VIVEMOS}

A integração entre os aspectos discutidos nos quatro módulos se deu em uma atividade de campo, ou estudo do meio, na bacia do rio Pirajuçara e seus principais afluentes, com a observação in loco e discussão dos aspectos do meio físico, dos aspectos históricos, de uso e ocupação, dos problemas sociais e ambientais.

As aulas de campo, como enfatizadas por Compiani \& Carneiro (I993), têm um papel pedagógico fundamental, pois é no campo que ocorre o conflito entre o real (o mundo), o exterior e o interior, as ideias e as representações, gerando um contexto único de observação e interpretação da natureza na busca de informações, no entendimento dos fenômenos e na formulação de conceitos explicativos. Segundo os autores, o campo é também o centro de atividades para ensinar o método geral de conceber a história geológica da Terra.

O estudo do meio é uma metodologia de ensino interdisciplinar que pretende desvendar a complexidade de um espaço determinado extremamente dinâmico e em constante transformação, cuja totalidade dificilmente uma disciplina escolar isolada pode dar conta de compreender (PONTUSCHKA et al., 2007).

$\mathrm{O}$ estudo do meio como método que pressupõe o diálogo, a formação de um trabalho coletivo e o professor como pesquisador de sua prática, de seu espaço, de sua história, da vida de sua gente, de seus alunos, tem como meta criar o próprio currículo da escola, estabelecendo vínculos com a vida de seu aluno e com a sua própria, como cidadão e como profissional. As autoras ressaltam que um projeto de ensino que usa essa metodologia realiza um movimento de apreensão do espaço social, físico e biológico que se dá em múltiplas ações combinadas e complexas. Para aprender a complexidade do real, faz-se necessária a existência de muitos olhares, da reflexão conjunta e de ações em direção ao objetivo proposto pelo grupo de trabalho (PONTUSCHKA et al., 2007).

$\mathrm{O}$ uso dessa metodologia para integrar as disciplinas é ideal para o ensino e a aprendizagem dos alunos, de forma a contextualizar os dados da realidade com os conteúdos. As intervenções pedagógicas de cada disciplina em particular contribuem para o conhecimento dos objetivos do estudo. O tema água pode ser abordado de várias maneiras no estudo do meio, 
dependendo dos objetivos propostos.

Para a realização do trabalho de campo, houve uma preparação dos professores em duas aulas que antecederam a atividade. Na primeira aula foram abordadas as metodologias utilizadas nas aulas de campo e de como elas podem ser inseridas no contexto dos projetos desenvolvidos em sala de aula. Os professores tiveram a oportunidade de relatar as atividades de campo que executam e de como elas são planejadas nas escolas, as dificuldades que apresentam em termos de infraestrutura e de quão importante elas são para o aprendizado dos alunos. Com isso ficou evidente a importância das aulas de campo para o aprendizado e de como ela pode ser utilizada em diferentes disciplinas de forma integrada, ou seja, uma mesma saída de campo pode abordar diferentes conteúdos. Foi ressaltado também pelos professores que as aulas de campo, desde seu planejamento até sua abordagem posterior, depois da saída, são uma forma de praticar a interdisciplinaridade. Nessa aula solicitamos aos professores que trouxessem registros fotográficos, documentos e materiais de pesquisa sobre a bacia hidrográfica para elaborarmos em conjunto a atividade de campo.

$\mathrm{Na}$ segunda aula preparatória não foi possível elaborar o roteiro de campo junto com os professores por limitação de tempo. Porém, alguns professores levaram fotografias antigas e documentos sobre as enchentes da bacia do rio Pirajuçara, que foram mostradas para os demais e auxiliaram na compreensão prévia sobre o local a ser visitado sob o ponto de vista histórico. Além disso, essa aula serviu como uma revisão dos aspectos discutidos ao longo do curso e que seriam abordados durante a atividade de campo.

$O$ roteiro foi elaborado como uma síntese do curso, com questões que direcionassem a observação e o registro dos professores. Durante a atividade, foi realizada uma coleta de dados com registro fotográfico e anotações dos professores para a elaboração de um roteiro que pudesse ser usado pelos professores em suas aulas, com a possibilidade de levar os alunos para realização de atividades, como estudo do meio. Foram realizadas observações sobre a qualidade das águas dos rios da bacia, da forma de ocupação e dos problemas ambientais gerados pelo não planejamento da sua ocupação, as obras estruturais realizadas pelo poder público (retificação de canais e piscinões).

A aula de campo ocorreu em parte da bacia hidrográfica do Pirajuçara, nos municípios de São
Paulo e Taboão da Serra. O percurso escolhido proporcionou a visita a trechos do rio e seus afluentes e a obras de retenção das cheias, em particular na avenida Eliseu de Almeida e nos chamados piscinões. Fomos acompanhados por um engenheiro do DAEE que nos permitiu o acesso a alguns dos piscinões da bacia e forneceu valiosas explicações técnicas do funcionamento dessas obras, da aplicação dos recursos financeiros pelo estado e prefeitura e, principalmente, a visão do poder público e as soluções que são propostas para a contenção das enchentes na bacia.

Foi possível ter uma noção integrada de como a ocupação da área em questão reflete na dinâmica do rio e de como o homem combate as enchentes e modifica os processos naturais, interferindo por meio de obras estruturais na dinâmica natural de todo o sistema hídrico.

Após a atividade de campo, realizamos uma discussão com os professores sobre suas observações e impressões. A principal discussão foi sobre as possibilidades de solucionar os problemas observados no local e sobre a complexidade social e ambiental vivenciada pela população da bacia hidrográfica.

A abordagem do tema em sala de aula e de metodologias de elaboração de projetos que contemplem a Educação Ambiental também foram discutidos com muito interesse pelos professores, que com a aula de campo puderam relacionar os conteúdos abordados no curso.

\section{USO DE FERRAMENTAS DIGITAIS: MOODLE E PÁGINA ELETRÔNICA DO TEIA-USP}

O uso de ferramentas digitais ampliou o envolvimento dos professores com a temática da inclusão digital na escola, em sala de aula e com referenciais de pesquisa bibliográfica. Durante o curso, os professores foram estimulados a usar o ambiente virtual como meio de comunicação entre o grupo e a página eletrônica do TEIA-USP na busca de referenciais teóricos sobre Educação Ambiental e Recursos Hídricos, temas centrais tratados durante as aulas.

O ambiente virtual Moodle é um serviço que a USP oferece aos seus docentes e alunos para a criação de disciplinas a distância ou como complementação de disciplinas presenciais.

Observamos que inicialmente houve certa resistência e dificuldade por parte dos professores em 
aderir à ferramenta, seja por falta de hábito, apontada por alguns, seja pelas dificuldades oferecidas pela própria plataforma de comunicação do ambiente virtual Moodle. No decorrer do curso, observamos que alguns professores desistiram de usar a ferramenta e outros acabaram usando-a apenas parcialmente, para envio de mensagens de correio eletrônico e para consulta de material disponível.

O uso de ferramentas desse tipo é importante para a comunicação e agilidade na disseminação de informações. No entanto, nesse caso específico, os resultados ficaram aquém do esperado. Identificamos alguns aspectos que contribuíram nesse sentido:

- pouca familiaridade dos professores com ambientes virtuais desse tipo;

- dificuldades para incluir textos produzidos no sistema, os quais, depois de digitados eram perdidos sem ser salvos, desmotivando uma nova produção;

- falta de acompanhamento e de intervenções diárias por parte da equipe de professores responsáveis pelo curso para estimular a participação dos alunos.

Apesar das dificuldades apresentadas, o uso do ambiente virtual foi mantido até o final do curso para que pudéssemos avaliar a contribuição dessa ferramenta. O ambiente virtual do Moodle não foi muito bem avaliado pelos alunos do curso, mas observamos que a consulta à página eletrônica do TEIA-USP e de outras páginas eletrônicas com referencial sobre Educação Ambiental aumentou. Os professores sentiram-se mais seguros em buscar informações nas páginas que lhes eram indicadas, trazendo essas informações para as discussões em classe e usando o seus conteúdo nas aulas.

Um dos bolsistas, Rodrigo Marinangelo, ficou responsável pela administração do ambiente virtual e pela inserção de materiais sobre Educação Ambiental na página eletrônica do TEIA-USP. Essa atuação foi essencial para a orientação dos professores que contaram com instruções detalhadas elaboradas pelo bolsista no início do curso. Além disso, ele serviu como referência para os professores tirarem suas dúvidas.

O desenvolvimento do curso permitiu uma nova reestruturação da página eletrônica do TEIA-USP e da divulgação mais ampla de materiais de referência em Educação Ambiental. Dessa forma, atingimos um público mais amplo e aliamos a formação de professores com a divulgação em Educação Ambiental. A atividade de extensão a que nos propomos no início do curso possibilitou a ampliação do público e a articulação entre um ambiente virtual, a universidade e a realidade escolar trazida pelos professores.

No ambiente virtual, também temos registradas as colocações dos professores, seus debates nos fóruns virtuais, fotografias antigas digitalizadas por eles, fotografias da aula de campo, documentos sobre o Pirajuçara. Esse material é essencial para uma continuidade do curso e pode servir para a elaboração de um material de divulgação sobre a bacia do Pirajuçara.

\section{CONSIDERAÇÕES FINAIS}

Apesar do pouco tempo de curso e das dificuldades encontradas, o curso nos trouxe algumas possibilidades de reflexão, produtos de divulgação em educação ambiental e a consolidação da página eletrônica do grupo TEIA-USP. Ao final do curso, percebemos que seria necessário um tempo muito mais longo para realizarmos uma investigação sobre a bacia do rio Pirajuçara junto aos alunos e para a construção de roteiros escolares mais aprofundados. A incorporação pelos professores das metodologias de ensino apresentadas durante o curso, principalmente a atividade de campo ocorreria depois da realização de outros campos e de análises mais minuciosas da realidade local, o que ainda poderá se consolidar. Já iniciamos o processo de levantamento de documentos sobre o local, que estão armazenados na página eletrônica e que podem ser utilizados em cursos futuros sobre a bacia do Pirajuçara.

Vale ressaltar a importância de atividades de ensino que congregam profissionais com diferentes formações e que convergem suas visões para um determinado tema. Nossa experiência nesse sentido, com o tema água, proporcionou aos participantes do curso uma compreensão da realidade local no sentido real da palavra ambiental, em suas múltiplas características que englobam o meio físico, o social, o histórico, o econômico e o político. Ao retomarmos as dúvidas iniciais dos professores, observamos que as discussões se enriqueciam à medida que as diferentes abordagens iam sendo feitas e ia se construindo uma visão complexa da realidade, com propostas mais efetivas para a abordagem do tema em sala de aula e para soluções das questões atuais.

Acreditamos que o curso tenha proporcionado 
aos participantes maior consistência nas abordagens do tema proposto e despertado uma vontade em continuar as pesquisas que fazem, melhorando sua prática com os alunos e aprofundando seus conteúdos, muito além das propostas curriculares atuais.

\section{REFERÊNCIAS BIBLIOGRÁFICAS}

BACGI, D. L. G.; PATACA, E. M. Educação para Água. Revista de Estudos Avançados, v. 22, n. 63, mai./ ago. 2008.

GANIL, K. Indicadores para monitoramento de processos morfodinâmicos: aplicação na bacia do Ribeirão Pirajussara (SP). São Paulo, 2006. Tese (doutorado). Faculdade de Filosofia, Letras e Giências Humanas, Universidade de São Paulo.

GOMPIANI, M.; GARNEIRO, G. R. Os papéis didáticos das excursões geológicas. Asociación Española para la Enseñanza de las Ciencias de La Tierra. v. I, n. 2, p. 90-98, I993.

COMPIANI, M. Geologia/Geociências no Ensino Fundamental e a Formação de Professores. Revista do Instituto de Geologia USP. Public. Espec., São Paulo, 2005, v. 3, p. I3-30.

DE LA GORTE, M.; FIGUEIREDO, R. L. A trajetória de uma inovação curricular entre duas disciplinas (Biologia e Geografia) a partir do ambiente local norteado pelo ciclo da água. In: I Simpósio de Pesquisa em Ensino e História de Giências da Terra. III Simpósio Nacional sobre Ensino de Geologia no Brasil. Campinas, São Paulo, 2007, p. 45-50.

FUNDAÇÃO SISTEMA ESTADUAL DE ANÁLISE DE DADOS: SEADE. 2007. Informações Socioeconômicas: Informações Municipais. São Paulo: SEADE. Disponível em: 〈http://www.seade.gov.br〉. Acesso em: I5 set. 2007.

HAGY, R. D.; VILLANOVA, G. L. Ciclo da água e a urbanização: um estudo do meio (microbacia de drenagem do córrego dos Campos) com alunos da terceira série do ensino médio. In: I Simpósio de Pesquisa em Ensino e História de Giências da Terra. III Simpósio Nacional sobre Ensino de Geologia no Brasil. Campinas, São Paulo, 2007, p. II9-I24.

INSTITUTO BRASILEIRO DE GEOGRAFIA E ESTATÍSTICA. IBGE, 2007. Dados preliminares do censo de 2007. Rio de Janeiro: IBGE, 2007. Disponível em: <http://www. ibge.gov.br/home>. Acesso em: I5 set. 2007.
INSTITUTO DE PESQUISAS TEGNOLÓGIGAS DO ESTADO DE SÃO PAULO. IPT. Bases técnicas para prevenção e controle da erosão na bacia do ribeirão $\mathbf{P i}$ rajussara, municípios de São Paulo, Taboão da Serra e Embu - Projeto Erosão Zero. São Paulo: IPT, 2004. (Relatório 68.387).

INSTITUTO DE PESQUISA EGONÔMICA APLICADA: IPEADATA, 2007. IPEADATA Regional e Social. São Paulo: IPEA. Disponível em: <http://www.ipeadata.gov. br/ipeaweb.dll/ipeadata $>$. Acesso em: 20 set.2007.

JACOBI, P. R. Educação ambiental, cidadania e sustentabilidade. Gadernos de Pesquisa. v. II8. FGG. São Paulo, 2003.

JACOBI, P. R. Gestão compartilhada de Recursos hídricos no Brasil e o desafio do fortalecimento de espaços públicos colegiados. In: Coelho, V.S.P. \& Nobre, M, org. Participação e deliberação: teoria democrática e experiências institucionais no Brasil contemporâneo. São Paulo, Editora 34, 2004, p. 270-289.

LEAL, A. G.; SUDO, H.; TORRES, E. G. Educação Ambiental na microbacia do córrego do Botafogo em Presidente Prudente (SP). In: VII Simpósio Brasileiro de Geografia Física Aplicada. I Fórum Latino-Americano de Geografia Física Aplicada. ANAIS. Curitiba, Paraná. Universidade Federal do Paraná, Departamento de Geografia, I997, v. I. p. 20I.

LUGATTO, L. G.; TALAMONI, J. L. B. A construção coletiva interdisciplinar em Educação Ambiental no ensino médio: a microbacia hidrográfica do ribeirão dos Peixes como tema gerador. Ciência \& Educação, 2007. v. I3, n. 3, p. 389-398.

OSTROWSKY, M. de S. B. Sistemática integrada para controle de inundações em sub-bacias hidrográficas urbanas. Estudo de caso: A bacia do Pirajuçara sob o enfoque da integração de obras com ações de educação e percepção ambiental. São Paulo, 2000. Tese (doutorado). Faculdade de Arquitetura e Urbanismo, Universidade de São Paulo.

PONTUSGHKA, N. N.; PAGANELLI, T. I.; GACETE, N. H. Para ensinar e aprender Geografia. I ed. São Paulo, Gortez, 2007.

PROJETO BACIAS IRMÃS. Disponível em: <http: \\www. baciasirmas.org.br>.

ROMERA e SILVA, P. A. Água: quem vive sem? DIFrh/ CNPq, São Paulo, 2003. Secretaria da Educação. Coordenadoria de Estudos e Normas Pedagógicas. Água Hoje e Sempre: Consumo Sustentável. São Paulo: SE/ CENP, 2004 , p. 256.

SEGRETARIA MUNIGIPAL DE PLANEJAMENTO: 
SEMPLA, 2007. Mapas e Dados: Quadros Demográficos. São Paulo. Disponível em: <http://sempla.prefeitura.sp.gov.br>. Acesso em: I5 set. 2007.

TEIA-USP. Disponível em: 〈www.teia.fe.usp.br>.

TEIXEIRA, W.;Toledo, M. G. M.; Fairchild, T. R.; Taioli, F, orgs. Decifrando a Terra. São Paulo, Imprensa Nacional, 2009.

TUNDISI, J. G. A Bacia Hidrográfica como Laboratório Experimental para o Ensino de Ciência, Geografia e Educação Ambiental. In: SCHIEL, Dietrich et al, orgs. O Estudo de Bacias Hidrográficas - Uma estratégia para Educação Ambiental. São Carlos: Rima Editora, 2002. v. I, p. I2-I7. 